\title{
Treatment Options for Urogenital Dysfunction in Parkinson's Disease
}

Amit Batla, MD DM",*

Natalie Tayim, BA MSC ${ }^{2}$

Mahreen Pakzad, FRCS ${ }^{2}$

Jalesh N. Panicker, MD, DM, FRCP

\author{
Address \\ ${ }^{*}, 1$ UCL Institute of Neurology, Queen Square, 7 Queen Square, London, WC1N 3BG, \\ UK \\ Email: a.batla@ucl.ac.uk \\ ${ }^{2}$ Department of Uro-Neurology, National Hospital for Neurology and Neurosur- \\ gery, Queen Square, London, UK \\ ${ }^{3}$ Department of Uro-Neurology, The National Hospital for Neurology and Neuro- \\ surgery and UCL Institute of Neurology, Queen Square, London, UK
}

Published online: 27 September 2016

(C) The Author(s) 2016. This article is published with open access at Springerlink.com

This article is part of the Topical Collection on Movement Disorders

Keywords Lower urinary tract - Detrusor overactivity · Urodynamics • Bladder diary Parkinson's disease - Erectile dysfunction

\section{Opinion statement}

Urogenital dysfunction is commonly reported in Parkinson's disease (PD), and history taking and a bladder diary form the cornerstone of evaluation. The assessment of lower urinary tract (LUT) symptoms include urinalysis, ultrasonography, and urodynamic studies and help to evaluate concomitant urological pathologies such as benign prostate enlargement. Antimuscarinic medications are the first line treatment for overactive bladder (OAB) symptoms and solifenacin has been specifically studied in PD. Antimuscarininc drugs may exacerbate PD-related constipation and xerostomia, and caution is advised when using these medications in individuals where cognitive impairment is suspected. Desmopressin is effective for the management of nocturnal polyuria which has been reported to be common in PD. Intradetrusor injections of botulinum toxin have been shown to be effective for detrusor overactivity, however, are associated with the risk of urinary retention. Neuromodulation is a promising, minimally invasive treatment for PD-related $O A B$ symptoms. Erectile dysfunction is commonly reported and first line treatments include phosphodiesterase- 5 inhibitors. A patient-tailored approach is required for the optimal management of urogenital dysfunction in PD. 
Parkinson's disease (PD) is a progressive neurodegenerative disorder characterized by motor complaints of slowness of movements, resting tremor, and gait imbalance; however, "non-motor symptoms" are commonly reported and have a tremendous impact on quality of life $[1,2]$. Lower urinary tract (LUT) symptoms are often reported by patients, either storage symptoms (urinary urgency, frequency, nocturia, with or without incontinence) or voiding symptoms (slow and/or interrupted stream, terminal dribble, hesitancy and straining) [3]. The prevalence of LUT symptoms varies according to the study cited and ranges between 38 and $71 \%$, being influenced by the stage of disease and presence of LUT-related comorbidities, and parallels other manifestations of autonomic dysfunction [4-7]. The presence of LUT symptoms is associated with an increased risk for falls [8], early institutionalization and escalating health-related costs [9]. Nocturia is the most common non-motor symptom in PD but the causes for nocturia in PD are poorly understood $[10,11]$.

Urodynamic studies may demonstrate reduced bladder capacity, poor compliance and detrusor overactivity (DO) in $43-93 \%$ of patients of $\mathrm{PD}$ patients [12-14]. A likely mechanism for $O A B$ symptoms in $\mathrm{PD}$ is disruption of the dopamine D1-GABAergic direct pathway and its GABAergic collateral to the micturition circuit [15-17], resulting in loss of inhibition of the micturition reflex and $\mathrm{OAB}$ symptoms. $\mathrm{OAB}$ symptoms correlate in severity with urodynamic abnormalities and dopaminergic deficit on dopamine transporter scans $[3,18]$. Nocturia additionally may also be due to nocturnal polyuria, characterized by increased nocturnal urine production more than $20-33 \%$ of the entire 24-h volume [19]. Sexual dysfunction (SD) is frequently reported in PD and negatively impacts quality of life of both patients and partners. Men most commonly experience erectile dysfunction (ED) and difficulties in ejaculation, and women report reduced vaginal lubrication, painful intercourse and incontinence during sexual activity [20]. Patients may also report alterations in sexual desire such as hyposexuality or hypersexuality. Motor symptoms of PD such as tremor, muscle rigidity, dyskinesia and bradykinesia can affect sexual performance and satisfaction [20]. The management options for bladder and sexual dysfunction are discussed in this article. This article does not contain any studies with human or animal subjects performed by any of the authors.

\section{Management of lower urinary tract dysfunction}

Despite the high prevalence of LUT symptoms and impact on quality of life, treatment options are currently limited and are often poorly tolerated or ineffective in PD. Most treatment options are derived from guidance around general management of LUT symptoms in neurological patients. Comprehensive history taking is a sound starting point, as this provides insight into whether patients have storage dysfunction or voiding dysfunction, or both. Patients often have other medical comorbidities and the medications prescribed for these may contribute to LUTS, for example, diuretics used for managing hypertension increase urinary urgency and frequency. A review of concomitant medications provides an opportunity to review a patient's "anticholinergic burden", and adding an antimuscarinic medication may increase the risk for falls, cognitive impairment and all-cause mortality [21]. Physical examination involves examining the abdomen, flank and pelvic and genital organs, and when appropriate, evaluating urogenital sensations, sacral cord-mediated reflexes (bulbocavernosus reflex, anal reflex) and anal sphincter tone and contractions. Digital rectal examination in a male patient allows evaluation of the size and consistency of the prostate gland.

The bladder diary, ideally maintained by the patient or carer for a period of time usually 3 days, provides prospective information in real-time about LUT symptoms about the fluid intake, urine output, time of voids and recorded indicators of bother and severity of symptoms. It is the only evaluation that provides information

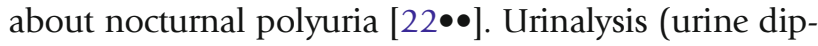
stick test) provides a rapid method of screening for Urinary tract infections (UTIs) which may share symptoms of OAB in the neurological population [23]. Ultrasonography is a non-invasive test that evaluates the lower and upper urinary tract for pathologies such as stones, hydronephrosis and prostate enlargement and also provides a measure of the post-void residual urine $[24 \bullet \bullet, 25,26 \bullet \bullet]$. Uroflowmetry is a non-invasive urodynamic study that provides information about voiding. It can be used to diagnose bladder outflow obstruction and assess the patient's flow rate, time and 


\begin{tabular}{|c|c|c|c|}
\hline & Bedside evaluation & Non-invasive tests & Invasive tests \\
\hline Essential & $\begin{array}{l}\text { History taking; physical } \\
\text { examination; bladder } \\
\text { diary }\end{array}$ & $\begin{array}{l}\text { Urinalysis; post-void residual } \\
\text { urine volume measurement; } \\
\text { ultrasonography }\end{array}$ & - \\
\hline Desirable & Questionnaires & Uroflowmetry; blood biochemistry & - \\
\hline $\begin{array}{l}\text { Required in } \\
\text { specific } \\
\text { situations }\end{array}$ & - & $\begin{array}{l}\text { Urine culture; urine cytology } \\
\text { Hormone profile (testosterone), } \\
\text { penile Doppler }\end{array}$ & $\begin{array}{l}\text { (Video-)urodynamics; flexible } \\
\text { cystoscopy; pelvic neurophysiology; } \\
\text { renal scintigraphy }\end{array}$ \\
\hline
\end{tabular}

pattern. Cystometry is not performed as a routine, however, may be required to evaluate the cause for LUT symptoms and exclude concomitant pathologies such

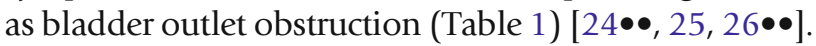

\section{Diet and lifestyle}

\section{Pharmacologic treatment}

\section{Antimuscarinic agents}

- Antimuscarinic agents are the first line treatment for OAB symptoms [31]. These include oxybutynin, tolterodine, solifenacin, darifenacin,

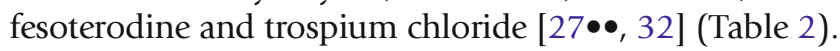

- Antimuscarinic agents competitively antagonize muscarinic acetylcholine receptors, prevent detrusor contraction, lower intravesical storage pressures and reduce storage symptoms.

The effect that these medications may have on central muscarinic

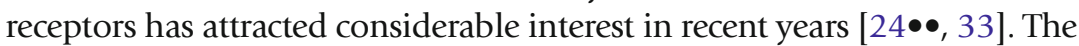
central effects of these medications may result in alterations in cognition and consciousness in susceptible individuals. Medications currently being used by the patient should be reviewed before prescribing an 


\begin{tabular}{|c|c|c|c|c|}
\hline Name & Dose in $\mathrm{mg}$ & Frequency & $\begin{array}{l}\text { Evidence for use in } \\
\text { neurogenic LUT } \\
\text { dysfunction }\end{array}$ & $\begin{array}{l}\text { Evidence } \\
\text { for } \\
\text { use in PD }\end{array}$ \\
\hline \multicolumn{5}{|l|}{ Antimuscarinic drugs } \\
\hline $\begin{array}{l}\text { Darifenacin-controlled } \\
\text { release }\end{array}$ & $7 \cdot 5-15$ & Once daily & NA & NA \\
\hline $\begin{array}{l}\text { Fesoterodine-controlled } \\
\text { release }\end{array}$ & $4-8$ & Once daily & NA & NA \\
\hline Oxybutynin & & & Level 1 & Level 5 \\
\hline Immediate release & $2 \cdot 5-5$ & $\begin{array}{l}\text { Two or three } \\
\text { times a day }\end{array}$ & & \\
\hline Controlled release & $5-20$ & Once daily & & \\
\hline Transdermal patch & $\begin{array}{r}36 \text { (releasing } \sim 3 \cdot 9 \mathrm{mg} \\
\text { oxybutynin per } 24 \mathrm{~h} \text { ) }\end{array}$ & $\begin{array}{l}\text { Replace once every } \\
\text { 3-4 days }\end{array}$ & & \\
\hline $\begin{array}{l}\text { Solifenacin-controlled } \\
\text { release }\end{array}$ & $5-10$ & Once daily & Level 2 & Level 2 \\
\hline Tolterodine & & & Level 3 & Level 5 \\
\hline Immediate release & $2-4$ & Once or twice daily & & \\
\hline Controlled release & 4 & Once daily & & \\
\hline Trospium chloride & & & Level 1 & Level 5 \\
\hline Immediate release & 20 & $\begin{array}{l}\text { Twice daily (before } \\
\text { food) }\end{array}$ & & \\
\hline Controlled release & 60 & Once daily & & \\
\hline \multicolumn{5}{|l|}{ Other drugs } \\
\hline Mirabegron & 25 to $50 \mathrm{mg}$ & Once daily & NA & NA \\
\hline Desmopressin & & & NA & Level 5 \\
\hline Nasal spray & 5 to $40 \mathrm{mcg} / \mathrm{day}$ & Once daily & & \\
\hline Tablets & $0.1 \mathrm{mg}$ & Once daily & & \\
\hline Injections & $4 \mathrm{mcg} / \mathrm{mL}$ & Once daily & & \\
\hline
\end{tabular}

antimuscarinic agent, especially in older people, as the cumulative use of agents with anticholinergic properties is associated with increased risk of cognitive impairment [33]. Permeability across the blood-brain barrier differs between antimuscarinic agents based upon physicochemical properties. For example, trospium chloride is a poorly lipophilic, positively charged quaternary ammonium compound that does not readily cross the blood-brain barrier and theoretically might be associated with fewer effects on cognition, though this has not been specifically evaluated in PD [34].

- Muscarinic receptor selectivity may influence central effects. For example, darifenacin has a greater affinity for the $\mathrm{M} 3$ receptor subtype of relevance to bladder functions compared to the M1 receptors prevalent in the central nervous system A recent double-blind, randomized, placebo-controlled study evaluated solifenacin in 23 patients with PD and urinary symptoms. There was no significant change in the mean number of micturition per $24 \mathrm{~h}$ 
period during the double-blind phase, but in the open label extension phase there was an improvement in the number of micturitions and number of

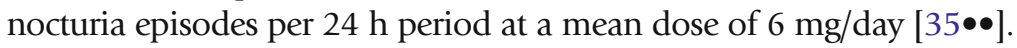

\section{Darifenacin [36]}

Standard dosage

Class of evidence

Contraindications

Main drug interactions

Main side effects

Special points
7. 5 to $15 \mathrm{mg}$ once daily.

NA [24••, 37]

Urinary retention; narrow angle glaucoma; gastric or intestinal obstruction, severe dementia or myasthenia gravis.

Preparations containing potassium can increase gastric intolerance, topiramate or zonisamide can increase chances of heat prostration.

Constipation, headache and xerostomia. Other side effects include urinary retention or tract infection and blurred vision. Anticholinergic central nervous system (CNS) effects are specifically relevant in elderly and patients with PD dementia.

Safety during pregnancy uncertain [Category C].

\section{Fesoterodine [36]}

Standard dosage

Class of evidence

Contraindications

Main drug interactions

Main side effects

Special points
4-8 mg once daily.

$5[24 \bullet \bullet, 37]$

Urinary retention; narrow angle glaucoma; gastric or intestinal obstruction, severe dementia or myasthenia gravis [38].

Preparations containing potassium can increase gastric intolerance, topiramate or zonisamide can increase chances of heat prostration.

Xerostomia (19-35\%), headache insomnia and constipation. Other side effects include urinary retention or tract infection and blurred vision. Anticholinergic CNS effects are specifically relevant in elderly and patients with PD dementia.

Safety during pregnancy uncertain [Category C].

\section{Oxybutinin [36]}

Standard dosage

Extended release tablets

Transdermal patch

Class of evidence

Contraindications

Main drug interactions

Main side effects

Special points
Immediate release tablet: $2.55 \mathrm{mg}$ two to three times daily.

5-20 mg daily.

$3.9 \mathrm{mg} /$ day, applied twice weekly (every 3 to 4 days).

Level 5 for urinary dysfunction in PD [11,37] [level 1 evidence for neurogenic detrusor overactivity [39]]

Urinary retention; narrow angle glaucoma; gastric or intestinal obstruction, severe dementia or myasthenia gravis [38].

Preparations containing potassium can increase gastric intolerance, topiramate or zonisamide can increase chances of heat prostration.

Constipation, headache and xerostomia. Other side effects include urinary retention or tract infection and blurred vision. Anticholinergic CNS effects are specifically relevant in elderly and patients with PD dementia.

Pregnancy category B. 


\section{Solifenacin $[36,40]$}

Standard dosage 5-10 mg orally per day

Class of evidence Level 1a for urinary dysfunction in PD [35••] (level 1 evidence for neurogenic detrusor overactivity [40].

Contraindications Urinary retention; narrow angle glaucoma; liver disease; kidney disease; intestinal obstruction; long QT syndrome.

Main drug interactions

Ketoconazole may significantly increase the blood levels of solifenacin, clozapine, citalopram, clarithromycin and other drugs that can prolong QT interval can increase the risk of arrhythmia with solifenacin

Main side effects Constipation and xerostomia. Other side effects include blurred vision and heat intolerance.

Special points Safety during pregnancy uncertain [Category C], reduced dose (5 mg/day) possible in hepatic and renal failure

\section{Tolterodine $[36,38]$}

Standard dosage $2 \mathrm{mg}$ twice a day or $4 \mathrm{mg}$ extended release capsule

Class of evidence Level 5 for urinary dysfunction in PD [37, 41•] [level 3 evidence for neurogenic detrusor overactivity [42]]

Contraindications Urinary retention; narrow angle glaucoma; gastric or intestinal obstruction, severe dementia or myasthenia gravis [38].

Main drug interactions

Preparations containing potassium can increase gastric intolerance, topiramate or zonisamide can increase chances of heat prostration.

Main side effects Constipation, dyspepsia, dizziness and xerostomia. Other side effects include urinary retention or tract infection and blurred vision. Anticholinergic CNS effects are specifically relevant in elderly and patients with PD dementia.

Special points Safety during pregnancy uncertain [Category C].

\section{Trospium chloride $[36,43]$}

Standard dosage

Class of evidence

Contraindications

Main drug interactions

Main side effects

Special points
$20 \mathrm{mg}$ twice a day or $60 \mathrm{mg}$ extended release capsule

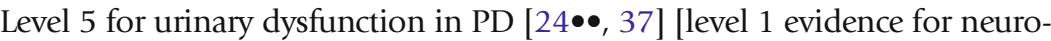
genic detrusor overactivity [43]]

Urinary retention; narrow angle glaucoma; gastric or intestinal obstruction, severe dementia or myasthenia gravis.

Preparations containing potassium can increase gastric intolerance, topiramate or zonisamide can increase chances of heat prostration.

Constipation, headache and xerostomia. Other side effects include urinary retention or tract infection and blurred vision. Anticholinergic CNS effects are specifically relevant in elderly and patients with PD dementia.

Safety during pregnancy uncertain [Category C]. 


\section{$\beta 3$-Adrenoceptor agonists}

(Mirabegron) [44, 45]

- Recently, mirabegron has emerged as a potentially safe and effective treatment for $\mathrm{OAB}[44]$ with preliminary evidence in neurogenic $\mathrm{OAB}$, though not specifically in PD [45]

- However, high-level evidence supporting the use of mirabegron in the management of the neurogenic bladder is lacking.

Standard dosage 25 to $50 \mathrm{mg}$ per day

Class of evidence NA [44]

Contraindications Patients with severe uncontrolled hypertension (BP $>180 / 110 \mathrm{mmHg}$ ) [46]

Main drug interactions Tamoxifen levels may be reduced in patients taking this for breast cancer

Main side effects Worsening of palpitation, preexisting hypertension and urinary retention

Special points Safety during pregnancy uncertain [Category C].

\section{Desmopressin}

- Desmopressin, a synthetic analogue of arginine vasopressin, temporarily reduces urine production and volume-related $\mathrm{OAB}$ symptoms.

Desmopressin works by promoting water reabsorption at the distal and collecting tubules of the kidney. It is useful for the treatment of urinary frequency or nocturia.

- Desmopressin has been tried in parkinsonism including PD and multiple system atrophy; however, long-term follow-up is lacking [38, 48, 47•, ].

Standard dosage Nasal spray 5 to $40 \mathrm{mcg} /$ day tablets $0.1 \mathrm{mg}$, injections $4 \mathrm{mcg} / \mathrm{mL}$

Class of evidence Level 5 [48]

Contraindications Kidney disease, cystic fibrosis, hyponatremia, heart failure and pedal edema. Used with caution over 65 years of age.

Main drug interactions

Antidepressants-citalopram, sertraline and duloxetine can increase chances of hyponatremia with desmopressin

Main side effects Headache, hyponatremia specifically relevant in patients older than 65 .

Special points Safety during pregnancy uncertain [Category C].

\section{Botulinum toxin}

Intradetrusor injection of onabotulinumtoxinA has proven to be a safe and effective treatment for neurogenic DO. In one study of 20 patients with DO moderate to marked symptom relief at 3 months and a $50 \%$ incontinence decrease over 6 months relative to pretreatment was reported in $59 \%$ patients $(p \leq 0.02)[49 \bullet \bullet]$. Another study of eight patients reported clinical and urodynamic improvement in overactive bladder symptoms that lasted at least 6 months in patients with PD [50]. In another study, 
Kulacksizoglu et al. reported no increase in post-voiding residual [51]. OnabotulinumtoxinA treatment results in impaired detrusor contractility and therefore is associated with a risk for urinary retention. The potential benefits of this treatment must be weighed against the potential need to intermittently catheterize or use an indwelling catheter, and the accompanying dependence on carers or partners and possible complications including urinary tract infection, trauma, bleeding, potential for lower limb weakness and flu-like illness.

\section{Assistive procedures}

\section{Clean intermittent self catheterization}

The finding of a high post-void residue (PVR) is unusual in patients with PD. If the PVR volume is consistently more than $100 \mathrm{~mL}$, clean intermittent catheterization has been advocated. Specific issues related to dexterity in PD may make this challenging. Experienced health-care professionals, such as a continence adviser, should be involved in teaching the technique and exploring possible barriers to successful catheterization. Complications include UTI and trauma $[26 \bullet \bullet, 52 \bullet]$.

\section{Neuromodulation}

- Percutaneous tibial nerve stimulation (PTNS) is an emerging treatment option that may help patients who have contraindications or are refractory to medical treatment. Following acute PTNS, the functional bladder capacity has been shown to be increased [53]. Chronic stimulation has been reported to decrease frequency, urinary and urge urinary incontinence in neurogenic bladder, but long term outcomes in PD are lacking [53]

- Transcutaneous tibial nerve stimulation (TTNS) was found effective in the treatment of LUT symptoms in 13 patients with PD, reducing urgency and nocturia [54]

- Sacral neuromodulation (SNM) may be effective and safe for the treatment of patients with neurogenic lower urinary tract dysfunction (LUTD). However, studies specifically in PD are lacking. A systematic review and meta-analysis included only four patients with PD and this group was not separately analysed. [55].

\section{Specific therapies for Parkinson's disease in management of urological dysfunction}

The effects of levodopa on LUT symptoms are variable [3, 56, 57]. There may be a period of initial worsening after starting levodopa but this may improve later [3]. One study showed that treatment with levodopa for 3 months in PD patients was associated with slightly improved storage urodynamic parameters [3]. In another study, DO was shown to worsen with levodopa in some patients and lessened in others. The effect on micturition of treatment with dopaminergic drugs in PD was unpredictable in another study [56]. Dopaminergic drugs 
like bromocriptine can lead to decreased storage parameters and pergolide improved nocturia in a small study [57].

In an open label study including three patients 12 weeks of treatment with pergolide improved LUT symptoms and nocturia frequency in all three patients and an improvement of sleep QOL in two [57].

Deep brain stimulation

DBS (DBS) is a well-accepted treatment option in advanced PD. Deep brain stimulation can have variable effects on LUT symptoms with worsening reported in some and improvement in other studies [58, 60, 59••, ]. Although the studies have not specifically focused on nocturia, there is evidence that subthalamic nucleus DBS-treated patients exhibit significantly less nocturia. In a study comparing DBS (GPi) and other forms of treatment in 107 patients with PD, the overall amount of urinary symptoms were similar but fewer DBS patients (47\%) complained of nocturia compared to conventionally treated ( $88 \%$ ) and to apomorphine pumptreated $(66 \%)$ patients [61]. Not only did the patients who had DBS reported less nocturia $(P=0.007)$ but also they were also less bothered by nocturia $(P=0.01)$ compared to the other treatment groups, as assessed by the Danish Prostate Symptom Score (DanPSS) [61]. More studies may be needed to establish definite correlation and to understand the pathophysiology of this association.

\section{Surgical therapies for bladder outflow obstruction}

Benign prostate enlargement is a common cause for bladder outflow obstruction in middle age and elderly men and is often a contributory factor for LUT dysfunction in PD. It was widely believed for several years that men with PD should not undergo prostate surgery because of the high risk of incontinence [62]. There is some evidence to support transurethral prostate resection for bladder outflow obstruction in patients with PD. In a study on 23 patients with PD, TURP was successful in up to $70 \%$. The risk of de novo urinary incontinence after surgery was reported as minimal $[63 \bullet \bullet]$.

\section{Management of sexual dysfunction}

Management of sexual dysfunction (SD) in patients with PD includes both behavioural and pharmacological options depending on the nature of the sexual dysfunction. Behavioural therapy may be used to treat SD, if considered as a learned maladaptive behaviour [64] and may involve the use of psychodynamic psychotherapy and cognitive behavioural therapy [64, $65 \bullet \bullet$. Pharmacological treatment of SD, on the other hand, requires either the reduction or elimination of drugs interfering with the sexual function or the introduction of drugs that improves sexual function [64, 65••]. Ultimately, treatment options for SD may require multidisciplinary input from neurologists and psychologists for optimum results [64]. Although phosphodiesterase 5 inhibitors (below) are standard treatment option for erectile dysfunction [66], intracavernosal alprostadil (prostaglandin E2) 1.25-10 $\mu$ g injections can be used.

The management of hypersexuality as part of an impulse control disorder includes reduction/stopping of dopamine receptor agonist and practical therapeutic strategies including psychological therapies but not limited to 
counselling, psychotherapy, sex, couple and behavioural therapies $[65 \bullet \bullet]$. Hormonal treatment specifically testosterone has been tried in PD [67].

\section{Sildanefil}

Standard dosage 25-100 mg taken $1 \mathrm{~h}$ before sexual activity

Class of evidence Level 5

Contraindications Hypotension (blood pressure below 90/50 mmHg)

Main drug interactions Organic nitrates in any form, alpha-blockers and antihypertensives may cause hypotension.

Main side effects Headache, flushing and dyspepsia. Temporary visual symptoms (mainly colour-vision disturbances) may occur with higher doses $100 \mathrm{mg}$

Special points Used once or twice per week.

\section{Tadalafil}

Standard dosage $10 \mathrm{mg}$ orally once a day, as needed, prior to sexual activity

Class of evidence Level 5

Contraindications Hypotension (blood pressure below 90/50 mmHg)

Main drug interactions Organic nitrates in any form, alpha-blockers and antihypertensives may cause hypotension.

Main side effects Headache, flushing and dyspepsia. Temporary visual symptoms (mainly colour-vision disturbances) may occur with higher doses $100 \mathrm{mg}$

Special points Used once or twice per week.

\section{Acknowledgments}

This work was undertaken at UCLH/UCL Institute of Neurology and JNP is supported in part by funding from the UK Department of Health NIHR Biomedical Research Centres funding scheme.

Parkinson's UK grant K-1303 has funded an ongoing project at the Department of Uroneurology- "Singlecentre open label exploratory phase two pilot study of exogenous oral Melatonin for the treatment of Nocturia in Parkinson's disease".

\section{Compliance with Ethical Standards}

\section{Conflict of Interest}

Amit Batla and Natalie Tayim each declare no potential conflicts of interest.

Mahreen Pakzad has been a speaker for Astellas.

Jalesh N. Panicker has received royalties from Cambridge University Press, has been involved in trials supported by FirstKind Ltd, Allergan and Ipsen and has received speaker honoraria from Wellspect, Astellas and Allergan. 
Human and Animal Rights and Informed Consent

This article does not contain any studies with human or animal subjects performed by any of the authors.

Open Access This article is distributed under the terms of the Creative Commons Attribution 4.0 International License (http://creativecommons.org/licenses/by/4.0/), which permits unrestricted use, distribution, and reproduction in any medium, provided you give appropriate credit to the original author(s) and the source, provide a link to the Creative Commons license, and indicate if changes were made.

\section{References and Recommended Reading}

Papers of particular interest, published recently, have been highlighted as:

- Of importance

$\bullet \quad$ Of major importance

1. Chaudhuri KR, Healy DG, Schapira AH, National Institute for Clinical E. Non-motor symptoms of Parkinson's disease: diagnosis and management. Lancet Neurol. 2006;5(3):235-45.

2. Pont-Sunyer C, Hotter A, Gaig C, Seppi K, Compta Y, Katzenschlager R, et al. The onset of nonmotor symptoms in Parkinson's disease (the ONSET PD study). Move dis: off J Move Dis Soc. 2015;30(2):229-37.

3. Sakakibara R, Tateno F, Kishi M, Tsuyuzaki Y, Uchiyama T, Yamamoto T. Pathophysiology of bladder dysfunction in Parkinson's disease. Neurobiol Dis. 2011.

4. Andersen JT. Disturbances of bladder and urethral function in Parkinson's disease. Int Urol Nephrol. 1985;17(1):35-41.

5. Sakakibara R, Tateno F, Kishi M, Tsuyuzaki Y, Uchiyama T, Yamamoto T. Pathophysiology of bladder dysfunction in Parkinson's disease. Neurobiol Dis. 2012;46(3):565-71.

6. Berger Y, Blaivas JG, DeLaRocha ER, Salinas JM. Urodynamic findings in Parkinson's disease. J Urol. 1987;138(4):836-8.

7. Magerkurth C, Schnitzer R, Braune S. Symptoms of autonomic failure in Parkinson's disease: prevalence and impact on daily life. Clin Auton Res. 2005;15(2):76-82.

8. Balash Y, Peretz C, Leibovich G, Herman T, Hausdorff JM, Giladi N. Falls in outpatients with Parkinson's disease: frequency, impact and identifying factors. J Neurol. 2005;252(11):1310-5.

9. McGrother CW, Jagger C, Clarke M, Castleden CM. Handicaps associated with incontinence: implications for management. J Epidemiol Community Health. 1990;44(3):246-8.

10. Cornu JN, Abrams P, Chapple CR, Dmochowski RR, Lemack GE, Michel MC, et al. A contemporary assessment of nocturia: definition, epidemiology, pathophysiology, and management - a systematic review and meta-analysis. Eur Urol. 2012;62(5):877-90.

11. Winge K, Fowler CJ. Bladder dysfunction in Parkinsonism: mechanisms, prevalence, symptoms, and management. Mov Dis: Off J Move Dis Soc. 2006;21(6):737-45.

12. Xue $\mathrm{P}$, Wang T, Zong H, Zhang Y. Urodynamic analysis and treatment of male Parkinson's disease patients with voiding dysfunction. Chin Med J. 2014;127(5):878-81.

13. Sakakibara R, Shinotoh H, Uchiyama T, Sakuma M, Kashiwado M, Yoshiyama M, et al. Questionnairebased assessment of pelvic organ dysfunction in Parkinson's disease. Aut Neurosci: Basic Clin. 2001;92(1-2):76-85.

14. Fitzmaurice H, Fowler CJ, Rickards D, Kirby RS, Quinn NP, Marsden CD, et al. Micturition disturbance in Parkinson's disease. Br J Urol. 1985;57(6):652-6.

15. Dalmose AL, Bjarkam CR, Sorensen JC, Djurhuus JC, Jorgensen TM. Effects of high frequency deep brain stimulation on urine storage and voiding function in conscious minipigs. Neurourol Urodyn. 2004;23(3):265-72.

16. Sakakibara R, Nakazawa K, Uchiyama T, Yoshiyama M, Yamanishi T, Hattori T. Effects of subthalamic nucleus stimulation on the micturation reflex in cats. Neuroscience. 2003;120(3):871-5.

17. Yamamoto T, Sakakibara R, Hashimoto K, Nakazawa K, Uchiyama T, Liu Z, et al. Striatal dopamine level increases in the urinary storage phase in cats: an in vivo microdialysis study. Neuroscience. 2005;135(1):299303.

18. Winge K, Friberg L, Werdelin L, Nielsen KK, Stimpel H. Relationship between nigrostriatal dopaminergic degeneration, urinary symptoms, and bladder control in Parkinson's disease. Eur J Neurol. 2005;12(11):84250.

19. Weiss JP, Blaivas JG, Bliwise DL, Dmochowski RR, Dubeau CE, Lowe FC, et al. The evaluation and treatment of nocturia: a consensus statement. BJU Int. 2011;108(1):6-21.

20. Bronner G, Vodusek DB. Management of sexual dysfunction in Parkinson's disease. Ther Adv Neurol Disord. 2011;4(6):375-83. 
21. Gerretsen P, Pollock BG. Rediscovering adverse anticholinergic effects. J Clin Psychiatry. 2011;72(6):86970 .

22.• Smith M, Seth J, Batla A, Hofereiter J, Bhatia KP, Panicker JN. Nocturia in patients with Parkinson's disease. Move Dis Clin Pract. 2016;3(2):168-72.

This recently published study highlights the importance of bladder diaries in identifying causes of nocturia in Parkinson's disease.

23. Phe V, Pakzad M, Curtis C, Porter B, Haslam C, Chataway J, et al. Urinary tract infections in multiple sclerosis. Mult Scler. 2016.

24.•Panicker JN, Fowler CJ, Kessler TM. Lower urinary tract dysfunction in the neurological patient: clinical assessment and management. Lancet Neurol.

2015;14(7):720-32.

This review article summarizes problems with management of LUT dysfunction and highlights the troubles with cholinergic burden in the elderly population.

25. Sakakibara R, Panicker J, Finazzi-Agro E, Iacovelli V, Bruschini H, The Parkinson's Disease Subcomittee TNPCiTICS. A guideline for the management of bladder dysfunction in Parkinson's disease and other gait disorders. Neurourol Urodynamics. 2015.

26.• NICE. Urinary incontinence in neurological disease: Management of lower urinary tract dysfunction in neurological disease. 2012.

National guidelines that summarize the approach to investigations and treatment of urinary incontinence in neurological diseases including PD.

27.• Buser N, Ivic S, Kessler TM, Kessels AG, Bachmann LM. Efficacy and adverse events of antimuscarinics for treating overactive bladder: network meta-analyses. Eur Urol. 2012;62(6):1040-60.

This article discusses the role of daily fluid intake and its effects on nocturia.

28. Griffiths DJ, McCracken PN, Harrison GM, Gormley EA. Relationship of fluid intake to voluntary micturition and urinary incontinence in geriatric patients. Neurourol Urodyn. 1993;12(1):1-7.

29. Weiss JP, Blaivas JG. Nocturia. J Urol. 2000;163(1):512.

30. Batla A, Phé V, De Min L, Panicker JN. Nocturia in Parkinson's disease: why does it occur and how to manage? Movement Disorders Clinical Practice. 2016: (online ahead of print).

This article summarizes the management of nocturia in PD.

31. Rackley R, Weiss JP, Rovner ES, Wang JT, Guan Z. Nighttime dosing with tolterodine reduces overactive bladder-related nocturnal micturitions in patients with overactive bladder and nocturia. Urology.

2006;67(4):731-6. discussion 6.

32. Madhuvrata $P$, Singh $M$, Hasafa Z, Abdel-Fattah M. Anticholinergic drugs for adult neurogenic detrusor overactivity: a systematic review and meta-analysis. Eur Urol. 2012;62(5):816-30.

33. Gray SL, Anderson ML, Dublin S, Hanlon JT, Hubbard $\mathrm{R}$, Walker R, et al. Cumulative use of strong anticholinergics and incident dementia: a prospective cohort study. JAMA Int Med. 2015;175(3):401-7.

34. Isik AT, Celik T, Bozoglu E, Doruk H. Trospium and cognition in patients with late onset Alzheimer disease. J Nutr Health Aging. 2009;13(8):672-6.

35.• Zesiewicz TA, Evatt M, Vaughan CP, Jahan I, Singer C, Ordorica R, et al. Randomized, controlled pilot trial of solifenacin succinate for overactive bladder in Parkinson's disease. Parkinsonism Relat Disord. 2015;21(5):514-20.

This is the only double-blind, randomized, placebo-controlled study evaluating an antimuscarinic agent in PD.

36. Urinary Incontinence UK: BNF; 2016. Available from: http://www.evidence.nhs.uk/formulary/bnf/current/7obstetrics-gynaecology-and-urinary-tract-disorders/74drugs-for-genito-urinary-disorders/742-drugs-forurinary-frequency-enuresis-and-incontinence/urinaryincontinence.

37. Winge K, Fowler CJ. Bladder dysfunction in Parkinsonism: mechanisms, prevalence, symptoms, and management. Mov Disord. 2006;21(6):737-45.

38. Hesch K. Agents for treatment of overactive bladder: a therapeutic class review. Proc (Baylor Univ Med Cent). 2007;20(3):307-14.

39. Gajewski JB, Awad SA. Oxybutynin versus propantheline in patients with multiple sclerosis and detrusor hyperreflexia. J Urol. 1986;135(5):966-8.

40. van Rey F, Heesakkers J. Solifenacin in multiple sclerosis patients with overactive bladder: a prospective study. Adv Urol. 2011;2011:834753.

41. Batla A, Panicker JN. Lower urinary tract dysfunction in Parkinson's disease and multiple system atrophy. Leading Opin Urol. 2013;17-22.

This article summarizes common causes and management options for urinary dysfunction in PD and MSA.

42. Ethans KD, Nance PW, Bard RJ, Casey AR, Schryvers OI. Efficacy and safety of tolterodine in people with neurogenic detrusor overactivity. J Spinal Cord Med. 2004;27(3):214-8.

43. Mazo EB, Babanina GA. [Trospium chloride (spasmex) in the treatment of lower urinary tract symptoms in patients with neurogenic hyperactive urinary bladder caused by vertebrogenic lesions]. Urologiia. 2007. (3):15-9.

44. Herschorn S, Barkin J, Castro-Diaz D, Frankel JM, Espuna-Pons M, Gousse AE, et al. A phase III, randomized, double-blind, parallel-group, placebo-controlled, multicentre study to assess the efficacy and safety of the beta(3) adrenoceptor agonist, mirabegron, in patients with symptoms of overactive bladder. Urology. 2013;82(2):313-20.

45. Phe V, Mukhtar B, Couchman A, Grewal M, Hamid R, Ockrim J, et al. Progres Urol: J Assoc Fr Urol Soc Fr Urol. 2015;25(13):845-6.

46. Mirabegron (Betmiga $\boldsymbol{\nabla}$ ): risk of severe hypertension and associated cerebrovascular and cardiac events: Medicines and Healthcare products Regulatory Agency; 2015 [updated 14 October 2015]. Available from: https://www.gov.uk/drug-safety-update/mirabegron- 
betmiga-risk-of-severe-hypertension-and-associatedcerebrovascular-and-cardiac-events.

47. Suchowersky O, Furtado S, Rohs G. Beneficial effect of intranasal desmopressin for nocturnal polyuria in Parkinson's disease. Move Dis: Off J Move Dis Soc. 1995;10(3):337-40.

An open label study that identified nocturnal polyuria as an important problem in PD which was treatable with intranasal desmopressin in all the patients who completed the study.

48. Mattiasson A, Abrams P, Van Kerrebroeck P, Walter S, Weiss J. Efficacy of desmopressin in the treatment of nocturia: a double-blind placebo-controlled study in men. BJU Int. 2002;89(9):855-62.

$49 . \bullet$ Anderson RU, Orenberg EK, Glowe P. OnabotulinumtoxinA office treatment for neurogenic bladder incontinence in Parkinson's disease. Urology. 2014;83(1):22-7.

Double blind placebo controlled trial of oral desmopressin in men with nocturia showing improvement.

50. Giannantoni A, Conte A, Proietti S, Giovannozzi S, Rossi A, Fabbrini G, et al. Botulinum toxin type A in patients with Parkinson's disease and refractory overactive bladder. J Urol. 2011;186(3):960-4.

51. Kulaksizoglu H, Parman Y. Use of botulinim toxin-A for the treatment of overactive bladder symptoms in patients with Parkinson's disease. Parkinsonism Relat Disord. 2010;16(8):531-4.

52. Seth JH, Haslam C, Panicker JN. Ensuring patient adherence to clean intermittent self-catheterization. Patient Preference Adherence. 2014;8:191-8.

This study evaluated the use of Intradetrusor injections of botulinum toxin in 16 patients with PD with improvements in quality of life.

53. Kabay SC, Kabay S, Yucel M, Ozden H. Acute urodynamic effects of percutaneous posterior tibial nerve stimulation on neurogenic detrusor overactivity in patients with Parkinson's disease. Neurourol Urodyn. 2009;28(1):62-7.

54. Perissinotto MC, D'Ancona CA, Lucio A, Campos RM, Abreu A. Transcutaneous tibial nerve stimulation in the treatment of lower urinary tract symptoms and its impact on health-related quality of life in patients with Parkinson disease: a randomized controlled trial. J Wound, Ostomy, Continence Nurse: Off Publ Wound, Ostomy Continence Nurse Soc/WOCN. 2015;42(1):94-9.

55. Kessler TM, La Framboise D, Trelle S, Fowler CJ, Kiss G, Pannek J, et al. Sacral neuromodulation for neurogenic lower urinary tract dysfunction: systematic review and meta-analysis. Eur Urol. 2010;58(6):865-74.

56. Winge K, Werdelin LM, Nielsen KK, Stimpel H. Effects of dopaminergic treatment on bladder function in Parkinson's disease. Neurourol Urodyn.

2004;23(7):689-96.
57. Kuno S, Mizuta E, Yamasaki S, Araki I. Effects of pergolide on nocturia in Parkinson's disease: three female cases selected from over 400 patients. Parkinsonism Relat Disord. 2004;10(3):181-7.

58. Seif C, Herzog J, van der Horst C, Schrader B, Volkmann J, Deuschl G, et al. Effect of subthalamic deep brain stimulation on the function of the urinary bladder. Ann Neurol. 2004;55(1):118-20.

$59 . \bullet$ Winge K, Nielsen KK, Stimpel H, Lokkegaard A, Jensen SR, Werdelin L. Lower urinary tract symptoms and bladder control in advanced Parkinson's disease: effects of deep brain stimulation in the subthalamic nucleus. Mov Disord. 2007;22(2):220-5.

In this series of 16 patients with PD who had subthalamic DBS, bladder sensitivity was shown to improve.

60. Finazzi-Agro E, Peppe A, D'Amico A, Petta F, Mazzone $P$, Stanzione $P$, et al. Effects of subthalamic nucleus stimulation on urodynamic findings in patients with Parkinson's disease. J Urol. 2003;169(4):1388-91.

61. Winge K, Nielsen KK. Bladder dysfunction in advanced Parkinson's disease. Neurourol Urodyn. 2012;31(8):1279-83.

62. Staskin DS, Vardi Y, Siroky MB. Post-prostatectomy continence in the parkinsonian patient: the significance of poor voluntary sphincter control. J Urol. 1988;140(1):117-8.

63.• Roth B, Studer UE, Fowler CJ, Kessler TM. Benign prostatic obstruction and Parkinson's disease-should transurethral resection of the prostate be avoided? J Urol. 2009;181(5):2209-13.

A study of 50 patients with PD who had TURP suggesting increased risk of incontinence following prostatectomy in the parkinsonian patient with lack of voluntary sphincter control.

64. Chaliha C, Dalton CM, Elneil S, Kessler TM. Evaluation and management of neurogenic sexual dysfunction. In: Fowler CJ, Panicker JN, Emmanuel A, editors. Pelvic organ dysfunction in neurological disease: clinical management and rehabilitation. Cambridge: Cambridge University Press; 2010. p. 153-65.

65.• Moore O, Bronner G, Giladi N. Sexuality in Parkinson's disease. In: Chaudhuri KR, editor. Non-motor symptoms of Parkinson's disease. Oxford: Oxford University Press; 2009. p. 225-40.

This book chapter details the common sexual problems in PD and highlights the treatment options.

66. Tbronner G, Vodušek DB. Management of sexual dysfunction in Parkinson's disease. Ther Adv Neurol Disord. 2011;4(6):375-83.

67. Okun MS, Fernandez HH, Rodriguez RL, et al. Testosterone therapy in men with Parkinson disease: results of the TEST-PD study. Arch Neurol. 2006;63(5):72935. 